\title{
The Effect of Lipoproteins on the Development and Progression of Renal Disease
}

\author{
Lorien S. Dalrymple $^{\mathrm{a}}$ George A. Kaysen ${ }^{\mathrm{a}-\mathrm{c}}$ \\ Departments of ${ }^{a}$ Medicine, and ${ }^{b}$ Biochemistry and Molecular Medicine, University of California, Davis, \\ and 'Department of Medicine, Department of Veterans Affairs Northern California Health Care System, \\ Sacramento, Calif., USA
}

\section{Key Words}

Lipids · Chronic kidney disease • Nephropathy, progression • Statins

\begin{abstract}
The field of research examining how lipoproteins may contribute to the development and/or progression of renal disease has rapidly expanded over the last 25 years. In animal models, lipoproteins and lipids have been associated with both the initiation and progression of renal disease. Numerous potential mechanisms of lipoprotein-induced renal injury have been identified by utilizing animal models and tissue-culture experiments. However, with the exception of rare genetic mutations, the association between lipoproteins and human renal disease is less clear. In humans, the evidence that lipid-lowering therapy delays renal progression is limited. The purpose of this paper is to review the current literature on lipoprotein abnormalities and the development or progression of renal disease.
\end{abstract}

Copyright $\odot 2008$ S. Karger AG, Base

\section{Introduction}

There has been a long-standing recognition of the potential relationship between lipoproteins and renal disease. Although a relationship between lipid abnormali-

\section{KARGER}

Fax +4161306 1234

E-Mail karger@karger.ch

www.karger.com
(C) 2008 S. Karger AG, Basel

0250-8095/08/0285-0723\$24.50/0

Accessible online at:

www.karger.com/ajn ties and renal disease was observed as early as the 19th century, research in this area has only broadly expanded over the last 25 years [1-3]. Currently, this is an area of active investigation as lipoproteins may contribute both to the initiation and progression of chronic kidney disease (CKD). CKD is associated with significant morbidity and mortality and identifying factors that contribute to the development or progression of renal disease, especially those factors that could be therapeutic targets, is of great importance.

Our current understanding of the potential pathogenic mechanisms of lipoproteins is derived from animal studies with mechanistic information contributed from studies conducted in tissue culture. In humans, a number of observational studies have found an association between abnormal lipoprotein levels with either the onset or progression of renal disease; however, the findings across studies have been inconsistent. The evidence is limited on the impact of lipid lowering therapy on renal progression.

The purpose of this paper is to review our current understanding of how lipoprotein and apolipoprotein abnormalities may contribute to the development and progression of renal disease. Despite the research to date, many questions remain unanswered regarding the importance of lipoproteins in the pathogenesis of human renal disease. Importantly, we make no attempt to address the potential effects of lipoprotein abnormalities on 
cardiovascular disease; the potential cardiovascular impact is a separate consideration when managing and treating patients with CKD.

\section{Overview}

Lipoproteins are composed of lipids and apoproteins. Lipoproteins are soluble both in lipid and aqueous phases allowing for the emulsification of lipids in plasma. They have a lipid core consisting of triglycerides and cholesterol esters, and an outer layer consisting of apolipoproteins, phospholipids and cholesterol. The distinct types of lipoproteins are: very-low-density (VLDL), low-density (LDL), intermediate-density (IDL) and high-density (HDL) lipoproteins, and chylomicrons [4]. Apolipoproteins are proteins associated with lipoproteins that have both hydrophobic and hydrophilic domains to facilitate micelle formation of insoluble lipids. These molecules also act as receptors for lipoprotein uptake and serve to facilitate the engagement between lipoproteins and receptors or enzymes that facilitate their metabolism. Each lipoprotein is associated with specific apolipoprotein(s) such as ApoB-48, ApoB-100, ApoA-I, ApoA-II, ApoE, ApoC-I, ApoC-II, or ApoC-III that act as recognition proteins for their cognate receptors and facilitate or inhibit interaction between lipoproteins and enzymes [4].

For the purposes of this review, lipoprotein disorders are generally classified into two distinct broad categories: disorders of lipid levels (such as hyperlipidemia or dyslipidemia), and abnormalities in apolipoprotein or lipoprotein structure (such as amino acid substitutions in apolipoproteins). Distinguishing between these categories is important in order to understand the mechanisms by which lipoprotein alterations may contribute to renal disease and provide a conceptual framework for understanding the current literature. A third potential categorization is lipoprotein composition or density; however, few studies have looked at the effect of lipoprotein density (e.g., small, dense LDL) or lipoprotein content (e.g., triglyceride content of HDL) on renal function, limiting our discussion primarily to alterations in lipoprotein levels or structure.

Most animal evidence suggests increased concentrations of lipoproteins, in particular triglyceride-rich lipoproteins, contribute to both the initiation and progression of glomerular injury in the rat. However, data in humans has not definitively established that abnormal lipoprotein levels contribute to either the development or progression of renal disease. In contrast, rare genetic ab- normalities that result in either structural alterations of apolipoproteins or in the absence of enzymes required for normal lipoprotein maturation can result in the development of renal disease in humans.

\section{Experimental Data}

\section{Initiation of Renal Disease}

Numerous animal studies have examined the role of lipoproteins in renal disease. These studies have demonstrated that lipoprotein abnormalities appear to cause primary renal injury and can contribute to the progression of established renal disease regardless of etiology. Both the obese Zucker rat (OZR) and rats with dietary induced hyperlipidemia serve as models for lipid abnormalities as initiators of renal disease.

The OZR is one of the primary animal models of endogenous hyperlipidemia that has been used to examine lipoprotein-mediated renal injury. The OZR develops hyperlipidemia, hyperinsulinemia, insulin resistance, obesity, and glomerulosclerosis. The lipoprotein abnormality, characterized primarily by hypertriglyceridemia, occurs prior to the development of renal disease and is believed to contribute to the observed proteinuria and glomerular injury [5]. In female OZRs, hyperphagia is associated with glomerular injury, and hyperphagia-induced hypertriglyceridemia precedes the renal injury [6]. Rats fed a diet high in saturated fat and cholesterol develop increased plasma VLDL and increased rates of glomerulosclerosis [7]. Several other lines of experimental evidence support that hypertriglyceridemia, as opposed to other nutritional or metabolic factors in the OZR, contributes to the observed glomerulosclerosis. The effect of diet and lipids can be separated in the OZR as well as in the Nagase Analbuminemic Rat (NAR) by the fact that estrogen is associated with increased VLDL production in the rat, and hence plays a non-nutritional role in establishing greater lipid levels in females than in males in the two models $[8,9]$. In both the OZR and NAR, renal injury and hypertriglyceridemia [10-13] occur in the females and can be delayed (in OZR) or prevented (in NAR) by oophrectomy.

\section{Progression of Renal Disease}

Numerous experimental studies have examined the effect of hypercholesterolemia on the progression of glomerular injury. Based on animal studies, the more important role of lipoproteins in renal disease may be in their contribution to the progression of renal disease as 
opposed to their role in initiating renal disease [14]. In animal models, diet-induced hypercholesterolemia in combination with pre-existing renal disease (secondary to hypertension, glomerular disease or reduced nephron mass) appears to have an additive or synergistic effect on renal injury with resultant increased glomerulosclerosis $[2,14]$.

\section{Effects of Lipid-Lowering Therapy}

One line of evidence regarding the importance of lipid levels comes from studies of lipid-lowering therapy in animal models. The hypothesis that lipids contribute to the renal injury observed in the OZR is further supported by the finding that treatment with different classes of lipidlowering agents, including clofibric acid and HMG CoA reductase inhibitors, decreases albuminuria, mesangial matrix formation, mesangial cellularity, and the percent of sclerotic glomeruli [15]. In the puromycin animonucleoside nephrosis model of glomerular injury with secondary hyperlipidemia, treatment with cholestyramine has been associated with a reduction of lipids early in the course of renal disease and with a subsequent decrease in proteinuria and development of segmental glomerulosclerosis [16]. Although HMG CoA Reductase inhibitors have pleiotropic renal effects [17] which may account for the observed improvement in functional and pathological outcomes, other classes of lipid-lowering therapy have been shown to improve renal pathologic findings and albuminuria. These findings in experimental models suggest the improvements may, in part, be mediated by lipid lowering.

\section{Potential Mechanisms of Injury}

Human mesangial cells and glomerular epithelial cells have been found to express LDL receptors and scavenger receptors under certain conditions [18]. LDL has been shown to have a biphasic effect on human mesangial cells: stimulating mesangial cell proliferation at lower concentrations and becoming cytotoxic at higher concentrations. This suggests mesangial cells modify LDL to form oxidized LDL, and this transformation is responsible for the observed change in LDL effect [19]. Mechanisms by which oxidized LDL may contribute to renal injury include stimulation of pro-inflammatory and pro-fibrotic cytokine production, cell apoptosis, and vasoconstriction [20, 21]. Additionally, IDL and VLDL have been shown to stimulate mesangial cell proliferation at lower concentrations and inhibit proliferation at higher con-

Lipoproteins and Renal Disease centrations [22]. Rat and human mesangial cells express lipoprotein lipase [23], which augments the binding of VLDL to rat mesangial cells and increases VLDL-induced mesangial cell proliferation and PDGF production [24]. VLDL may also stimulate monocyte influx [25].

Numerous parallels have been drawn between the mechanisms underlying atherosclerosis and glomerulosclerosis [1]. Atherogenic lipoproteins are hypothesized to stimulate a series of events that result in mesangial cell proliferation and extracellular matrix expansion (ECM), key components of proposed lipid injury models include: (1) the conversion of lipoproteins to oxidized lipoproteins by mesangial cells and macrophages; (2) oxidized LDL promotion of the production of cytokines, reactive oxygen species, and vasoactive substances; (3) oxidized LDL stimulation of apoptosis, and (4) macrophage influx, and matrix production $[1,21]$. Foam cells are lipid-filled macrophages that result from inflammatory cytokines and lipids. They produce cytokines and matrix metalloproteinases and can potentially influence mesangial cell proliferation and matrix formation [26]. Foam cells have been observed in areas of glomerulosclerosis and in the interstitium of various glomerular diseases $[27,28]$ and are also observed in atherosclerotic lesions, providing further support for a potential pathologic link between atherosclerosis and glomerulosclerosis [1].

Although plausible mechanisms for lipoprotein-mediated injury have been developed and animal models support the hypothesis that lipoproteins may cause renal injury, lipoprotein metabolism varies among species and it is important to highlight that there are significant differences which may limit the extrapolation of animal data to human disease models. As previously mentioned, rats serve as the primary animal models for lipoprotein-related renal disease, but the composition, structure, and function of lipoproteins differ between humans and rats. For example, in humans, VLDL is secreted by the liver and this is dependent on ApoB-100. VLDL is metabolized to a remnant particle (IDL) through an interaction with lipoprotein lipase on the vascular endothelium. It is then converted to LDL, which is taken up by the LDL receptor-recognizing ApoB-100 or is taken up directly by the LDL receptor-related protein (LRP), a receptor that targets ApoE, in the liver or other tissues. LDL is formed through the interaction of IDL with HDL and is dependent on cholesterol ester transfer protein (CETP) activity [4]. In contrast, the rat lacks CETP, and the LDL formed contains ApoE and is not equivalent to human LDL. Additionally, VLDL secreted by rat liver may contain either ApoB-100 or ApoB-48, a molecule that is not recognized 
by the LDL receptor and is committed to metabolism by the LRP. In contrast to the LDL receptor, the LRP is found in multiple tissues, including vascular tissues, so that proteins engaging this receptor have a greater opportunity to interact with endothelial and mesangial cells [29]. Differences in lipoprotein composition and function may, in part, explain why findings in animal studies differ from those in human studies.

\section{Human Studies}

As outlined above, lipoprotein abnormalities can be classified on the basis of level, structure or composition. Familial lecithin-cholesterol acyltransferase (LCAT) deficiency and lipoprotein glomerulopathy are both examples of abnormal apolipoprotein or lipoprotein structure and have been associated with the development of renal disease. In contrast, a direct causal relationship between abnormal lipid levels and renal injury has not been clearly established.

\section{LCAT Deficiency}

LCAT is an enzyme important in the esterification of free cholesterol, the formation and maturation of HDL, and reverse cholesterol transport [30]. Familial LCAT deficiency is an autosomal recessive disease secondary to mutations in the LCAT gene. Clinical manifestations include low HDL, increased LDL and free cholesterol, corneal opacifications, anemia, hemolysis, and renal injury secondary to accumulation of lipids in renal structures [31]. Renal disease secondary to familial LCAT deficiency has been shown to recur after renal transplantation [31, 32]. Pathologic renal findings include prominent foam cells in the capillaries and mesangium, mesangial expansion and, in more advanced cases, segmental sclerosis [33]. LCAT deficiency results in elevated levels of phosphatidylcholine and unesterified cholesterol and the accumulation of lipoprotein-X, an aberrant lipoprotein [34]. Although this disorder is associated with a dyslipidemia, lipoprotein-X appears to be involved in the pathogenesis of the glomerulopathy seen with LCAT deficiency $[35,36]$.

\section{Lipoprotein Glomerulopathy}

Lipoprotein glomerulopathy is a rare condition that was first described in 1989. Affected persons lack the classic clinical features seen in other lipidoses, such as xanthomas or ophthalmologic abnormalities, but they have significantly increased plasma ApoE levels, protein- uria, and can progress to end-stage renal failure. Hyperlipidemia is not universally present in patients with this disorder; however, the cholesterol content of VLDL and IDL is increased. On renal pathology, dilated glomerular capillaries with lipoprotein thrombi are present and foam cells are absent $[37,38]$. Lipoprotein glomerulopathy is thought to be related to ApoE abnormalities [39], and has been associated with numerous ApoE mutations [38-40]. The associated amino acid changes in ApoE would be expected to result in significant structural protein modifications.

Abnormally constructed ApoE may interact with other proteins to cause renal injury, similar to that which occurs in hereditary forms of amyloidosis involving ApoA-I and ApoA-II. Alterations in the structure of apolipoproteins can produce important structural modifications in these proteins that alter the way they interact with receptors and/or polymerize or cross link. Numerous ApoA-I gene mutations have been associated with systemic amyloidosis [41], and several mutations of ApoAI have been associated with amyloidosis with predominant renal manifestations [41-44]. Amyloidosis secondary to ApoA mutations exemplifies how conformational changes can affect apolipoprotein structure and function, resulting in renal disease.

\section{Familial Hyperlipoproteinemias}

Familial hyperlipoproteinemias, characterized by elevated lipid levels, have rarely been associated with renal manifestations. In one case report, familial combined hyperlipidemia with secondary hypothyroidism was associated with lipid deposits in mesangial and endothelial cells; after treatment with lipid-lowering therapy and hormone replacement, the lipid deposits were improved on subsequent renal biopsy [45]. Familial type III hyperlipoproteinemia, characterized by elevated levels of triglycerides and cholesterol, and traditionally associated with systemic manifestations such as xanthomas has rarely been associated with glomerulopathy $[37,46]$. No specific conclusions can be drawn given the paucity of data and the rare reports of renal disease associated with familial hyperlipoproteinemias.

\section{Observational Studies Examining Lipoprotein and Apolipoprotein Levels}

Observational studies in humans have primarily examined the association between levels of lipoproteins and the development and/or progression of renal disease, although some studies have examined lipoprotein composition. Observational studies in humans have produced 
inconsistent results and they are difficult to directly compare because of differences in study populations, the lipoproteins and apolipoproteins of interest, definitions of renal disease or progression, the outcome of interest (albuminuria vs. functional renal changes), ascertainment of potential confounders, and follow-up time. Below we review studies which have examined the relationship between lipoproteins and renal disease, but first we highlight several important issues.

As is widely known, the metabolic syndrome is associated with elevated triglycerides, decreased HDL levels, and alterations in the distribution of LDL size, with a shift towards a smaller and denser form of LDL [47]. The metabolic syndrome also consists of specific processes that are undeniably linked to renal injury: hypertension and glucose intolerance. Insulin resistance and metabolic syndrome are potentially confounding factors and must be considered in studies that include subjects with these conditions. Reflecting on the overlap in these conditions underscores the complexity of studying the relationship between lipoprotein abnormalities and renal disease.

Importantly, kidney disease is a well-known cause of dyslipidemia. Established CKD is associated with an abnormal lipid profile and alterations in lipoproteins. The dyslipidemia is characterized by modestly increased triglyceride levels, decreased HDL, and generally normal levels of cholesterol. Increases in both chylomicron and VLDL remnant particles (which make-up the IDL fraction) are observed. Significant structural alteration of lipoproteins is observed and these alterations may be more substantial than the change in lipoprotein levels. The observed densities of LDL and HDL are altered in CKD, with both LDL and HDL having a shift to smaller and denser isoforms. The content of lipoproteins is changed; the triglyceride content of HDL and the cholesterol content of VLDL and chylomicrons is increased. Additionally, Lp(a) lipoprotein levels are increased [48]. Given that CKD may cause a change in lipoproteins and lipids, the possibility of reverse causality must be considered in studies that include participants with renal disease.

With respect to examining specific lipids or lipoproteins, it is important to note that the metabolism of lipoproteins is interdependent and levels of certain lipids and lipoproteins are strongly associated. For example, triglycerides are strongly associated with small, dense LDL and a decrease in the $\mathrm{HDL}_{2}$ subfraction of HDL [49]. As described below, studies have found the association between triglycerides and renal dysfunction to be of variable significance, depending on whether other lipoproteins were

Lipoproteins and Renal Disease adjusted for in the statistical model. This is important to consider when determining whether it is triglycerides themselves or other lipoprotein abnormalities that are highly associated with triglycerides that are of primary interest.

A recent study by de Boer et al. [50] is very informative when considering observational studies to date. de Boer et al. examined cystatin $\mathrm{C}$ concentration, lipid levels, and LDL particle size (using nuclear magnetic resonance) among Multi-Ethnic Study of Atherosclerosis (MESA) participants with eGFRs $\geq 60 \mathrm{ml} / \mathrm{min} / 1.73 \mathrm{~m}^{2}$. They adjusted for gender, diabetes, impaired fasting glucose, blood pressure, BMI, albuminuria and other covariates, and then found that higher cystatin $\mathrm{C}$ was associated with increases in triglyceride levels and small LDL and IDL particles, and decreases in HDL levels and the mean LDL particle size. Because of the cross-sectional design of this study causality cannot be established. However, a possible interpretation of these findings is that the dyslipidemia associated with changes in renal function are present very early in the course of renal dysfunction and may promote renal injury. This study's novel findings highlight the complexity of examining this issue and show the limitations of the renal function measures used most commonly in observational studies.

Distinguishing between the initiation and progression of renal disease can be difficult and the distinction can, at times, be arbitrary. However, for the purposes of this review we will try to distinguish between those studies that have looked primarily at the development versus the progression of renal disease with respect to lipoprotein and lipid abnormalities. In addition, we will distinguish between the development of microalbuminuria and the development of functional renal decline as the primary outcome of interest.

The Physicians' Health Study and Atherosclerosis Risk in Communities Study (ARIC) Cohorts are two of the largest cohorts in which the relationship between lipoprotein levels and the development of renal dysfunction has been examined. Schaeffner et al. [51] examined 4,483 Physicians' Health Study participants during a 14-year follow-up period. After adjustment for covariates and examining each cholesterol variable separately, low HDL, high total cholesterol, elevated non-HDL cholesterol and an elevated ratio of total cholesterol to HDL were associated with an increased risk of renal insufficiency (which was defined as a serum creatinine $\geq 1.5 \mathrm{mg} / \mathrm{dl}$ ). Muntner et al. [52] examined 12,728 male and female subjects in the ARIC cohort with baseline creatinines $<2.0 \mathrm{mg} / \mathrm{dl}$ and $<1.8 \mathrm{mg} / \mathrm{dl}$, respectively. The primary outcome of in- 
terest was a serum creatinine rise $>0.4 \mathrm{mg} / \mathrm{dl}$ over baseline during a mean follow-up of 3 years. In multivariate analyses examining the role of each lipoprotein separately, both elevated triglycerides and decreased HDL were associated with an increased risk of rise in serum creatinine. However, when both HDL and triglycerides were included in the same statistical model, only triglycerides remained significantly associated with a serum creatinine rise. No association between total cholesterol, LDL, Lp(a), ApoA, or ApoB levels and rise in serum creatinine was observed. Interestingly, a separate analysis that was restricted to non-diabetic subjects found that the association between high triglycerides and increase in serum creatinine was significantly attenuated and no longer statistically significant after adjustment for fasting insulin levels. As highlighted by the authors, the study could not differentiate initiation from early progression of renal disease and there was a potential for reverse causality. Furthermore, baseline urinary protein measures and BMI were not adjusted for in the model, potentially confounding the observed relationship.

Some observational studies have examined the development of microalbuminuria, as opposed to change in renal function, and have been restricted to people with diabetes. Among people with type 2 diabetes, elevated total cholesterol and low HDL levels have both been shown to predict the development of microalbuminuria [53]. In people with type 1 diabetes, elevated triglyceride levels have been associated with the development of microalbuminuria, although interestingly this effect was eliminated when HDL was added to the statistical model, and neither lipoprotein remained significantly associated with the development of microalbuminuria [54].

Studies in selected groups at high risk for the development of kidney disease have also examined the association between lipid levels and the development of CKD. In a study of 230 lung transplant recipients who had well preserved renal function prior to transplant, LDL (the highest quartile) measured 6 months post-transplant was associated with a significantly increased risk of developing CKD (defined as eGFR $<30 \mathrm{ml} / \mathrm{min} / 1.73 \mathrm{~m}^{2}$ ) during follow-up. This finding persisted despite taking into account numerous factors including the type of calcineurin inhibitor and levels of immunosuppression above the mean value of the cohort [55].

In established renal disease, primary or secondary lipoprotein abnormalities may theoretically contribute to renal disease progression [26]. As previously outlined, specific abnormalities of lipoprotein distribution and composition are more common among persons with es- tablished CKD and these abnormalities may be associated with a continued decline in renal function. In the Modification of Diet in Renal Disease (MDRD) Study, Hunsicker et al. [56] examined the relationship between total cholesterol, HDL, LDL, ApoA-1 and ApoB and the progression of renal insufficiency. A total of 840 subjects with prevalent renal insufficiency were followed for up to 3.5 years for progression of renal disease, defined by change in GFR slope. In this study, a lower HDL was independently associated with progression; however, HDL appeared to only account for a small degree of the observed variance and to be primarily significant in those subjects with a GFR of $25-55 \mathrm{ml} / \mathrm{min} / 1.73 \mathrm{~m}^{2}$.

Few studies have examined cohorts with a single cause of renal disease, a design which potentially limits the unmeasured or residual confounding introduced by diverse renal diseases. Syrjanen et al. [57] examined a cohort of 181 subjects with IgA nephropathy and normal renal function. In this cohort, hypertriglyceridemia was independently associated with an increased risk of progression, defined as a $20 \%$ increase above baseline values and a serum creatinine above gender-specific normal ranges.

Conversely, several studies have failed to find an association between lipid or lipoprotein levels and the risk of renal progression. Boes et al. [58] examined 177 subjects with nondiabetic renal disease and followed the cohort for a median of 53 months. The investigators found an association between apolipoprotein A-IV levels and progression, but found no association between plasma levels of HDL or triglycerides and renal progression, defined as a doubling of serum creatinine or renal failure requiring initiation of renal replacement therapy. Massy et al. [59] prospectively followed a cohort of 138 subjects with established renal disease and monitored subjects for the development of ESRD requiring dialysis therapy. Neither HDL nor triglyceride levels were statistically significantly associated with the development of ESRD; however, there was a trend towards significance for elevated triglyceride levels and the risk of ESRD $(p=0.06)$.

In addition to examining levels of lipids and lipoproteins, some investigators have attempted to examine the role of lipoprotein composition. In order to extend on previous work suggesting ApoB levels may be associated with renal progression [60], Samuelsson et al. [61] examined the relationship between ApoB-containing lipoproteins and renal progression. The investigators studied a small cohort of non-diabetic subjects and examined the association between the composition of ApoB-containing lipoproteins and renal decline. The study found a 
strong correlation between the level of complex, triglyceride rich ApoB-containing lipoproteins and the rate of renal decline, whereas a significant correlation was not shown between cholesterol-rich ApoB-containing lipoproteins and renal decline. This study suggested that it may be apolipoprotein composition and not apolipoprotein levels that mediate renal injury from lipoproteins, which is an important conceptual model for studying the relationship between lipoproteins and renal disease. However, this study was performed in a small cohort and the observed findings may have been confounded.

Of additional interest are findings from a study among subjects with type 1 diabetes that suggested the effect of lipoproteins may differ depending on the stage of nephropathy. Among subjects with normoalbuminuria, progression [defined as a doubling of the microalbumin excretion ratio (MER) and an albumin excretion rate (AER) $>10 \mu \mathrm{g} / \mathrm{min}$ ] was associated with LDL-free cholesterol. Among subjects with microalbuminuria, progression (defined as a doubling of the AER) was associated with the triglyceride content of IDL and VLDL. However, among subjects with macroalbuminuria, progression (defined as $>3 \mathrm{ml} / \mathrm{min}$ per year decline in renal function) was associated with LDL size [62]. Although these observed associations are of interest, there is no clear causality and the findings raise important questions as to whether particular lipid abnormalities are indicators of more advanced renal injury.

\section{Effects of Lipid-Lowering Therapy}

Numerous studies have attempted to examine the effect of lipid-lowering therapies on either proteinuria or renal progression in humans. The vast majority of these studies have been conducted using HMG CoA Reductase inhibitors and we will therefore focus on the literature pertaining to this class of drugs.

A complete review of all the treatment trials with HMG CoA Reductase inhibitors conducted to date is beyond the scope of this review; however, two meta-analyses have recently been performed which aid in summarizing the effect of statins on proteinuria and renal progression. Douglas et al. [63] examined 15 randomized placebo-controlled trials with a total of 1,384 subjects with normoalbuminuria, microalbuminuira, or macroalbuminuria/proteinuria. The investigators found that despite selecting only randomized, controlled trials, the studies were not considered to be of high quality. In this analysis, statins were associated with a moderate reduction in proteinuria among those with microalbuminuira or macroalbuminuria/proteinuria, suggesting that statins

Lipoproteins and Renal Disease may improve urinary protein excretion. However, the investigators felt further studies were needed and their findings were not conclusive because of limitations of the data.

Sandhu et al. [64] examined the effect of HMG CoA Reductase inhibitors on renal progression in randomized, controlled or cross-over studies. Twenty-one of these studies examined renal progression and a total of 38,867 subjects were included. These investigators also found the available studies to not be of high quality. In this analysis, statin use was associated with a slowing in the rate of loss of renal function of $1.2 \mathrm{ml} / \mathrm{min}$ per year. However, if the findings from a single atorvastatin study were removed from the analysis, the pooled results showed only a $0.4 \mathrm{ml} / \mathrm{min}$ per year slower loss of renal function; and if only high quality trials were included, only a $0.2 \mathrm{ml} / \mathrm{min}$ per year slower loss of renal function. Given the significant heterogeneity in the initial pooled analysis, sub-populations were examined. In these analyses only those subjects with cardiovascular disease were found to have a statistically significant slowing of renal progression, whereas those subjects with diabetes, glomerulonephritis (GN), or hypertension did not have significant slowing of renal progression. Overall these findings suggest that, based on current evidence, statin use may result in a small protective effect; however, this has not been clearly demonstrated in people with established renal disease (such as GN) or in those with risk factors for renal disease (such as diabetes or hypertension).

Although HMG CoA Reductase inhibitors potentially decrease proteinuria and slow renal progression, their renoprotective effect may not be related to their lipidlowering effects. HMG CoA Reductase inhibitors are agents known to have pleiotropic effects and this class of drug may improve endothelial function and have antiinflammatory, anti-thrombotic, anti-oxidant, and immunomodulatory properties [17]. Distinguishing the pleiotropic effects from the lipid lowering effects is difficult, and although this line of evidence is important to the general care of persons with renal disease, it does not necessarily support a direct role of lipid-mediated renal injury.

\section{Conclusions}

In summary, whether lipoproteins contribute to the development or progression of human renal disease is unknown. This has become an active and important area of investigation, and significant progress has been made 
in this field of research. However, many questions remain unanswered. To a large extent, the true lipid or lipoprotein exposure of interest remains undefined. For example, we still have not defined which lipoproteins are particularly pathogenic in human renal disease and do not know whether it is the lipoprotein level or the lipoprotein composition that is key in renal toxicity. If lipoprotein levels are the most important factor, we do not know if there is a dose effect or if the duration of exposure is important. Furthermore, levels of specific lipoproteins are poor indicators of biological processes that may be occurring at a site of injury (e.g., impaired reverse cholesterol transport, inhibition of oxidative injury, or other func- tions). Studies need to be undertaken to more fully investigate the true exposure of interest, address potential reverse causality, and adequately account for confounders. Further exploration is needed in order to understand the relationship between lipoprotein abnormalities and renal injury.

\section{Acknowledgements}

This research was supported in part by the Research Service of the Department of Veterans Affairs. We would like to thank Dr. Ian de Boer for his review of the manuscript and his thoughtful suggestions.

\section{References}

$\checkmark 1$ Kamanna VS, Roh DD, Kirschenbaum MA: Hyperlipidemia and kidney disease: concepts derived from histopathology and cell biology of the glomerulus. Histol Histopathol 1998;13:169-179.

-2 Keane WF, Mulcahy WS, Kasiske BL, Kim Y O’Donnell MP: Hyperlipidemia and progressive renal disease. Kidney Int Suppl 1991; 31:S41-S48.

3 Moorhead JF, Chan MK, El-Nahas M, Varghese Z: Lipid nephrotoxicity in chronic progressive glomerular and tubulo-interstitial disease. Lancet 1982;2:1309-1311.

$\checkmark 4$ Vaziri ND: Dyslipidemia of chronic renal failure: the nature, mechanisms, and potential consequences. Am J Physiol Renal Physiol 2006;290:F262-F272.

5 Kasiske BL, O’Donnell MP, Keane WF: The Zucker rat model of obesity, insulin resistance, hyperlipidemia, and renal injury. Hypertension 1992;19(1 suppl):I110-I115.

6 Gades MD, Van Goor H, Kaysen GA, Johnson PR, Horwitz BA, Stern JS: Brief periods of hyperphagia cause renal injury in the obese Zucker rat. Kidney Int 1999;56:17791787.

7 Grone HJ, Walli A, Grone E, Niedmann P, Thiery J, Seidel D, Helmchen U: Induction of glomerulosclerosis by dietary lipids. A functional and morphologic study in the rat. Lab Invest 1989;60:433-446.

$>8$ Shearer GC, Joles JA, Jones H, Walzem RL, Kaysen GA: Estrogen effects on triglyceride metabolism in analbuminemic rats. Kidney Int 2000;57:2268-2274.

$>9$ Joles JA, Bijleveld C, van Tol A, Geelen MJ, Koomans HA: Ovariectomy decreases plasma triglyceride levels in analbuminaemic rats by lowering hepatic triglyceride secretion. Atherosclerosis 1995;117:51-59.
10 Joles JA, van Goor H, Koomans HA: Estrogen induces glomerulosclerosis in analbuminemic rats. Kidney Int 1998;53:862-868.

11 Joles JA, van Goor H, van der Horst ML, van Tol A, Elema JD, Koomans HA: High lipid levels in very low density lipoprotein and intermediate density lipoprotein may cause proteinuria and glomerulosclerosis in aging female analbuminemic rats. Lab Invest 1995; 73:912-921.

12 Stevenson FT, Wheeldon CM, Gades MD, Kaysen GA, Stern JS, van Goor H: Estrogen worsens incipient hypertriglyceridemic glomerular injury in the obese Zucker rat. Kidney Int 2000;57:1927-1935.

13 Gades MD, Stern JS, van Goor H, Nguyen D, Johnson PR, Kaysen GA: Estrogen accelerates the development of renal disease in female obese Zucker rats. Kidney Int 1998;53: 130-135.

14 Keane WF, Guijarro C: Lipids and progressive renal failure. Contrib Nephrol 1996;118: 17-23.

15 Kasiske BL, O’Donnell MP, Cleary MP, Keane WF: Treatment of hyperlipidemia reduces glomerular injury in obese Zucker rats. Kidney Int 1988;33:667-672.

16 Diamond JR, Hanchak NA, McCarter MD, Karnovsky MJ: Cholestyramine resin ameliorates chronic aminonucleoside nephrosis. Am J Clin Nutr 1990;51:606-611.

17 Epstein M, Campese VM: Pleiotropic effects of 3-hydroxy-3-methylglutaryl coenzyme a reductase inhibitors on renal function. Am J Kidney Dis 2005;45:2-14.

18 Takemura T, Yoshioka K, Aya N, Murakami K, Matumoto A, Itakura H, Kodama T, Suzuki H, Maki S: Apolipoproteins and lipoprotein receptors in glomeruli in human kidney diseases. Kidney Int 1993;43:918-927.
19 Keane WF, O’Donnell MP, Kasiske BL, Kim Y: Oxidative modification of low-density lipoproteins by mesangial cells. J Am Soc Nephrol 1993;4:187-194.

20 Heeringa P, Tervaert JW: Role of oxidized low-density lipoprotein in renal disease. Curr Opin Nephrol Hypertens 2002;11:287293.

21 Keane WF: The role of lipids in renal disease: future challenges. Kidney Int Suppl 2000;75: S27-S31.

22 Nishida Y, Yorioka N, Oda H, Yamakido M: Effect of lipoproteins on cultured human mesangial cells. Am J Kidney Dis 1997;29: 919-930.

23 Irvine SA, Martin J, Hughes TR, Ramji DP: Lipoprotein lipase is expressed by glomerular mesangial cells. Int J Biochem Cell Biol 2006;38:12-16.

24 Stevenson FT, Shearer GC, Atkinson DN: Lipoprotein-stimulated mesangial cell proliferation and gene expression are regulated by lipoprotein lipase. Kidney Int 2001;59:20622068.

25 Lynn EG, Siow YL, O K: Very low-density lipoprotein stimulates the expression of monocyte chemoattractant protein-1 in mesangial cells. Kidney Int 2000;57:1472-1483.

26 Abrass CK: Cellular lipid metabolism and the role of lipids in progressive renal disease. Am J Nephrol 2004;24:46-53.

27 Magil AB, Frohlich JJ, Innis SM, Steinbrecher UP: Oxidized low-density lipoprotein in experimental focal glomerulosclerosis. Kidney Int 1993;43:1243-1250.

28 Magil AB: Interstitial foam cells and oxidized lipoprotein in human glomerular disease. Mod Pathol 1999;12:33-40.

$29 \mathrm{Hu}$ C, Oliver JA, Goldberg MR, Al-Awqati Q: LRP: A new adhesion molecule for endothelial and smooth muscle cells. Am J Physiol Renal Physiol 2001;281:F739-F750. 
-30 Calabresi L, Pisciotta L, Costantin A, Frigerio I, Eberini I, Alessandrini P, Arca M, Bon GB, Boscutti G, Busnach G, Frasca G, Gesualdo L, Gigante M, Lupattelli G, Montali A, Pizzolitto S, Rabbone I, Rolleri M, Ruotolo G, Sampietro T, Sessa A, Vaudo G, Cantafora A, Veglia F, Calandra S, Bertolini S, Franceschini G: The molecular basis of lecithin: cholesterol acyltransferase deficiency syndromes: a comprehensive study of molecular and biochemical findings in 13 unrelated Italian families. Arterioscler Thromb Vasc Biol 2005;25:1972-1978.

-31 Panescu V, Grignon Y, Hestin D, Rostoker G, Frimat L, Renoult E, Gamberoni J, Grignon G, Kessler M: Recurrence of lecithin cholesterol acyltransferase deficiency after kidney transplantation. Nephrol Dial Transplant 1997; 12:2430-2432.

- 32 Horina JH, Wirnsberger G, Horn S, Roob JM, Ratschek M, Holzer H, Pogglitsch H, Krejs GJ: Long-term follow-up of a patient with lecithin cholesterol acyltransferase deficiency syndrome after kidney transplantation. Transplantation 1993;56:233-236.

33 Fogo AB, Kashgarian M: Diagnostic Atlas of Renal Pathology. Spain, Elsevier Saunders, 2005, pp 171-174.

-34 Frasca GM, Soverini L, Tampieri E, Franceschini G, Calabresi L, Pisciotta L, Preda P, Vangelista A, Stefoni S, Bertolini S: A 33year-old man with nephrotic syndrome and lecithin-cholesterol acyltransferase (LCAT) deficiency. Description of two new mutations in the LCAT gene. Nephrol Dial Transplant 2004;19:1622-1624.

-35 Zhu X, Herzenberg AM, Eskandarian M, Maguire GF, Scholey JW, Connelly PW, Ng DS: A novel in vivo lecithin-cholesterol acyltransferase (LCAT)-deficient mouse expressing predominantly LpX is associated with spontaneous glomerulopathy. Am J Pathol 2004;165:1269-1278.

-36 O K, Ly M, Fang DZ, Frohlich J, Choy PC: Effect of lipoprotein-X on lipid metabolism in rat kidney. Mol Cell Biochem 1997;173: 17-24.

-37 Saito T: Abnormal lipid metabolism and renal disorders. Tohoku J Exp Med 1997;181: 321-337.

-38 Matsunaga A, Sasaki J, Komatsu T, Kanatsu K, Tsuji E, Moriyama K, Koga T, Arakawa K, Oikawa S, Saito T, Kita T, Doi T: A novel apolipoprotein E mutation, E2 (Arg25Cys), in lipoprotein glomerulopathy. Kidney Int 1999;56:421-427.

-39 Oikawa S, Matsunaga A, Saito T, Sato H, Seki T, Hoshi K, Hayasaka K, Kotake H, Midorikawa H, Sekikawa A, Hara S, Abe K, Toyota T, Jingami H, Nakamura H, Sasaki J: Apolipoprotein E Sendai (arginine $145 \rightarrow$ proline): A new variant associated with lipoprotein glomerulopathy. J Am Soc Nephrol 1997;8: 820-823.
40 Ando M, Sasaki J, Hua H, Matsunaga A, Uchida K, Jou K, Oikawa S, Saito T, Nihei H: A novel 18-amino acid deletion in apolipoprotein E associated with lipoprotein glomerulopathy. Kidney Int 1999;56:13171323.

41 Murphy CL, Wang S, Weaver K, Gertz MA, Weiss DT, Solomon A: Renal apolipoprotein A-I amyloidosis associated with a novel mutant Leu64Pro. Am J Kidney Dis 2004;44: 1103-1109.

42 Persey MR, Booth DR, Booth SE, van ZylSmit R, Adams BK, Fattaar AB, Tennent GA, Hawkins PN, Pepys MB: Hereditary nephropathic systemic amyloidosis caused by a novel variant apolipoprotein A-I. Kidney Int 1998;53:276-281.

43 Soutar AK, Hawkins PN, Vigushin DM, Tennent GA, Booth SE, Hutton T, Nguyen O, Totty NF, Feest TG, Hsuan JJ, et al: Apolipoprotein AI mutation Arg-60 causes autosomal dominant amyloidosis. Proc Natl Acad Sci USA 1992;89:7389-7393.

44 Vigushin DM, Gough J, Allan D, Alguacil A, Penner B, Pettigrew NM, Quinonez G, Bernstein K, Booth SE, Booth DR, et al: Familial nephropathic systemic amyloidosis caused by apolipoprotein AI variant Arg26. Q J Med 1994;87:149-154.

45 Abe T, Kondo T, Suzuki A, Yamamoto H, Watanabe N, Kuroda R, Fukazawa Y, Kawakami Y: A case of glomerular lipidosis accompanied by familial combined hyperlipidemia and panhypopituitarism. Intern Med 1992;31:44-49.

46 Suzaki K, Kobori S, Ueno S, Uehara M, Kayashima T, Takeda H, Fukuda S, Takahashi K, Nakamura N, Uzawa H, et al: Effects of plasmapheresis on familial type III hyperlipoproteinemia associated with glomerular lipidosis, nephrotic syndrome and diabetes mellitus. Atherosclerosis 1990;80:181-189.

47 Garber AJ: The metabolic syndrome. Med Clin North Am 2004;88:837-846, ix.

48 Kaysen GA: Hyperlipidemia in chronic kidney disease. Int J Artif Organs, in press.

49 Brunzell JD: Clinical practice. Hypertriglyceridemia. N Engl J Med 2007;357:10091017.

50 de Boer IH, Astor BC, Kramer H, Palmas W, Seliger SL, Shlipak MG, Siscovick DS, Tsai MY, Kestenbaum B: Lipoprotein Abnormalities Associated with Mild Impairment of Kidney Function in the Multi-Ethnic Study of Atherosclerosis. Clin J Am Soc Nephrol 2008;3:125-132.

51 Schaeffner ES, Kurth T, Curhan GC, Glynn RJ, Rexrode KM, Baigent C, Buring JE, Gaziano JM: Cholesterol and the risk of renal dysfunction in apparently healthy men. J Am Soc Nephrol 2003;14:2084-2091.

52 Muntner P, Coresh J, Smith JC, Eckfeldt J, Klag MJ: Plasma lipids and risk of developing renal dysfunction: the atherosclerosis risk in communities study. Kidney Int 2000;58: 293-301.
Ravid M, Brosh D, Ravid-Safran D, Levy Z, Rachmani R: Main risk factors for nephropathy in type 2 diabetes mellitus are plasma cholesterol levels, mean blood pressure, and hyperglycemia. Arch Intern Med 1998;158: 998-1004.

54 Hadjadj S, Duly-Bouhanick B, Bekherraz A, Bridoux F, Gallois Y, Mauco G, Ebran J, Marre M: Serum triglycerides are a predictive factor for the development and the progression of renal and retinal complications in patients with type 1 diabetes. Diabetes Metab 2004;30:43-51.

55 Stephany BR, Alao B, Budev M, Boumitri M, Poggio ED: Hyperlipidemia is associated with accelerated chronic kidney disease progression after lung transplantation. Am J Transplant 2007;7:2553-2560.

56 Hunsicker LG, Adler S, Caggiula A, England BK, Greene T, Kusek JW, Rogers NL, Teschan PE: Predictors of the progression of renal disease in the Modification of Diet in Renal Disease Study. Kidney Int 1997;51: 1908-1919.

57 Syrjanen J, Mustonen J, Pasternack A: Hypertriglyceridaemia and hyperuricaemia are risk factors for progression of IgA nephropathy. Nephrol Dial Transplant 2000;15:34-42.

58 Boes E, Fliser D, Ritz E, König P, Lhotta K, Mann JF, Müller GA, Neyer U, Riegel W, Riegler P, Kronenberg F: Apolipoprotein AIV predicts progression of chronic kidney disease: the mild to moderate kidney disease study. J Am Soc Nephrol 2006;17:528-536.

59 Massy ZA, Nguyen Khoa T, Lacour B, Descamps-Latscha B, Man NK, Jungers P: Dyslipidaemia and the progression of renal disease in chronic renalfailure patients. Nephrol Dial Transplant 1999;14:2392-2397.

60 Samuelsson O, Mulec H, Knight-Gibson C, Attman PO, Kron B, Larsson R, Weiss L, Wedel H, Alaupovic P: Lipoprotein abnormalities are associated with increased rate of progression of human chronic renal insufficiency. Nephrol Dial Transplant 1997;12: 1908-1915.

61 Samuelsson O, Attman PO, Knight-Gibson C, Larsson R, Mulec H, Weiss L, Alaupovic P: Complex apolipoprotein B-containing lipoprotein particles are associated with a higher rate of progression of human chronic renal insufficiency. J Am Soc Nephrol 1998; 9:1482-1488.

62 Thomas MC, Rosengard-Barlund M, Mills V, Ronnback M, Thomas S, Forsblom C, Cooper ME, Taskinen MR, Viberti G, Groop $\mathrm{PH}$ : Serum lipids and the progression of nephropathy in type 1 diabetes. Diabetes Care 2006;29:317-322.

63 Douglas K, O’Malley PG, Jackson JL: Metaanalysis: the effect of statins on albuminuria. Ann Intern Med 2006;145:117-124.

64 Sandhu S, Wiebe N, Fried LF, Tonelli M: Statins for improving renal outcomes: a meta-analysis. J Am Soc Nephrol 2006;17: 2006-2016. 